\title{
Recovery of coral populations after the 1998 bleaching on Shiraho Reef, in the southern Ryukyus, NW Pacific
}

\author{
Hajime Kayanne $^{1, *}$, Saki Harii ${ }^{2}$, Yoichi Ide ${ }^{3, * *}$, Fujio Akimoto $^{4}$ \\ ${ }^{1}$ Department of Earth and Planetary Science, University of Tokyo, Hongo, Tokyo 113-0033, Japan \\ ${ }^{2}$ Department of Mechanical and Environmental Informatics, Tokyo Institute of Technology, Ookayama, Tokyo 152-8552, Japan \\ ${ }^{3}$ Marine Ecological Institute Co. Ltd., Haradamotomachi, Osaka 561-0808, Japan \\ ${ }^{4}$ Fuyo Ocean Development \& Engineering Co. Ltd., Kuramae, Tokyo 111-0051, Japan
}

\begin{abstract}
The most extensive and severe bleaching of coral ever recorded occurred in 1997 and 1998 as a result of anomalously high sea-surface temperatures. In the Ryukyu Islands, extensive bleaching occurred from late July to early October in 1998. A time-series transect study on a reef flat revealed the different responses of coral populations among species to this event. Coral cover was monitored just before, during, and 6 times after the bleaching occurred, along 5 fixed transects, 710 to $800 \mathrm{~m}$ long, across the reef flat of Shiraho Reef, Ishigaki Island, in the Ryukyu Islands of Japan. The dominant corals were Heliopora coerulea, massive Porites, and branching Porites, Montipora, Acropora, and Pavona (these latter 4 genera could not always be distinguished to species level, and are thus grouped by genus and ecoform). $H$. coerulea was the least susceptible to bleaching and maintained almost constant coverage before and after the bleaching. Massive Porites were susceptible to bleaching, but regained their algae after the bleaching and sustained their coverage. On the other hand, the branching Porites, Montipora, and Acropora were susceptible to bleaching and mortality was high. Coverage by branching Montipora was initially reduced by $66 \%$, but by 2 yr after the bleaching it had recovered to pre-bleaching coverage. However, only large patches of more than $70 \mathrm{~m}$ along a transect, with coverage of 10 to $40 \%$, recovered. Small patches of less than $30 \mathrm{~m}$ along a transect, with coverage of less than $10 \%$, died and did not recover. The response of corals to bleaching differs according to the strategy the coral uses against bleaching; moderately frequent and severe bleaching might permit the coexistence of both types of corals on the same reef flat, as in the case of Shiraho Reef.
\end{abstract}

KEY WORDS: Coral reef $\cdot$ Bleaching $\cdot$ Recovery $\cdot$ Population $\cdot$ Ryukyu Islands

\section{INTRODUCTION}

The high sea-surface temperatures that occurred in tropical regions from 1997 to 1998 led to the most extensive coral bleaching ever recorded (Wilkinson 1998, 2000, Hoegh-Guldberg 1999, Wilkinson et al. 1999, Aronson et al. 2000, Goreau et al. 2000, McClanahan 2000, Reaser et al. 2000). It is believed that the El Niño Southern Oscillation, which occurred in

\footnotetext{
*E-mail: kayanne@eps.s.u-tokyo.ac.jp

** Present address: Oceanic Planning Corporation, Kasuya, Fukuoka 811-2304, Japan
}

the period from late 1997 to early 1998, was probably behind these temperature anomalies. The underlying global warming trend is also thought to be related to this extreme event (Reaser et al. 2000). It is anticipated that global warming will cause increasingly frequent and severe bleaching of coral reefs in the future (Hoegh-Guldberg 1999).

The recovery of corals to their pre-bleaching levels has been inferred to take from 10 to $30 \mathrm{yr}$ for damaged coral populations and from 5 to $10 \mathrm{yr}$ for bleached corals that do not die (Hoegh-Guldberg 1999, Wilkinson et al. 1999). A change in community structure, i.e. from species susceptible to bleaching to species less 
susceptible to bleaching or from coral-dominated to macroalgal-dominated reefs, has also been predicted (Done 1999, Hoegh-Guldberg 1999). Contrary to these predictions, an unexpectedly fast recovery was reported for some coral reefs due to the survival of juvenile coral or new recruits (Normile 2000a,b). At this point, however, the actual process and its controlling factors are not fully understood, and we cannot predict with certainty how long a reef will take to recover and what factors control changes in community structure. This information is particularly important for evaluating the future response of coral reefs to increasingly frequent bleaching events.

Previous studies have revealed that the response of corals to bleaching varies among species. The fastgrowing, branching coral species of Acropora, Montipora, and Pocillopora are more susceptible to bleaching and have a higher mortality than the massive species of Porites and Favia, which are more tolerant of bleaching (Fisk \& Done 1985, Harriott 1985, Brown \& Suharsono 1990, Gleason 1993, Hoegh-Guldberg \& Salvat 1995, Marshall \& Baird 2000, McClanahan 2000, McClanahan et al. 2001). Recently, the variation in response has also been interpreted as resulting from physiological and genetic variation of the symbiotic algae, which have differing susceptibilities to thermal stress (Jones 1997, Baker 2001, Glynn et al. 2001, Kinzie et al. 2001), which then leads to intraspecific and spatial variation in the coral response to bleaching. Once corals bleach, they regain symbionts more tolerant to thermal stress, and consequently corals in a region exposed to frequent stress acclimate to it (Glynn et al. 2001, Hueerkamp et al. 2001).

In considering the susceptibility and recovery of coral populations, 3 aspects of the coral response to bleaching should be distinguished: susceptibility to bleaching, mortality resulting from bleaching (or tolerance and reacquisition of algae after bleaching), and recovery after mortality. The extent of bleaching has been reported as the percentage of bleached corals (susceptibility to bleaching) in some studies, and as the percentage mortality of corals in other studies. Few studies have reported both values. The term 'recovery' after bleaching has often been used to mean the reacquisition of symbiotic algae after bleaching, which represents the tolerance potential of corals after bleaching and differs from 'recovery' after mortality. In this paper, we use 'recovery' to mean recovery after mortality, which is achieved by sexual recruitment and asexual regrowth (overgrowth or fragmentation) of corals. These processes may differ among species and act differently in the course of changes in coral populations, and should be distinguished.

Most studies have focused on only one form of susceptibility, mortality or the reacquisition of algae by individual colonies in a single observation or during short-term observations. Relatively few studies have investigated the recovery process after mortality due to bleaching, as such studies require a time-series survey. Brown \& Suharsono (1990) reported recovery 5 yr after bleaching occurred in 1983, on coral reef flats in the Java Sea, and pointed out that the recovery was constrained by the initial community structure and the substratum condition for recruitment. McClanahan (2000) compared coral recruits with the original populations $1 \mathrm{yr}$ after the 1998 bleaching event, and discussed the implications for recovery potential and possible changes in community structure. In the eastern Pacific region, the response after the 1997 to 1998 bleaching event was compared with the response after the 1982 to 1983 bleaching. Vargas-Ángel et al. (2001) found that the variation in recovery was due to the difference in the degree of stress during the 2 events. Guzmán \& Cortés (2001) traced the change in coral cover over the last $15 \mathrm{yr}$ in Costa Rica and pointed out that not only bleaching, but also other disturbances, have suppressed the recovery of coral cover.

To understand the process of recovery and the factors controlling the recovery of corals, we must know how inter-specific differences in the response change the community structure of coral reefs on a population scale in the course of recovery from bleaching. This paper presents the results of a 2 yr time-series, transect study before, during, and after the 1998 bleaching on a reef flat of Shiraho Reef, on Ishigaki Island in the Ryukyu Islands of Japan (see Fig. 1). We had the opportunity to survey coral coverage just before the bleaching event in 1998, and subsequently repeated surveys along fixed transects. This revealed the susceptibility, mortality, and recovery of coral populations. We observed different recovery patterns according to coral species and patch size.

\section{MATERIALS AND METHODS}

Study site. Ishigaki Island is situated at the southernmost end of the Ryukyu Islands of Japan (Fig. 1). On Ishigaki Island, 359 coral species have been recorded, almost the same number as found in the Philippine Islands, in the core zone of coral distribution (Veron 1992). Shiraho Reef, on the southeast coast of Ishigaki Island (Fig. 2), had flourishing corals with no signs of deterioration, which was unique in the Ryukyu Islands (Takahashi et al. 1985, Kühlmann 1988, Planck et al. 1988, Mezaki 1991, Veron 1992). There is a dense population of the blue coral Heliopora coerulea that is regarded as containing the world's oldest and largest known colonies (Planck et al. 1988). Takahashi et al. (1985) surveyed the coverage of corals along a transect 


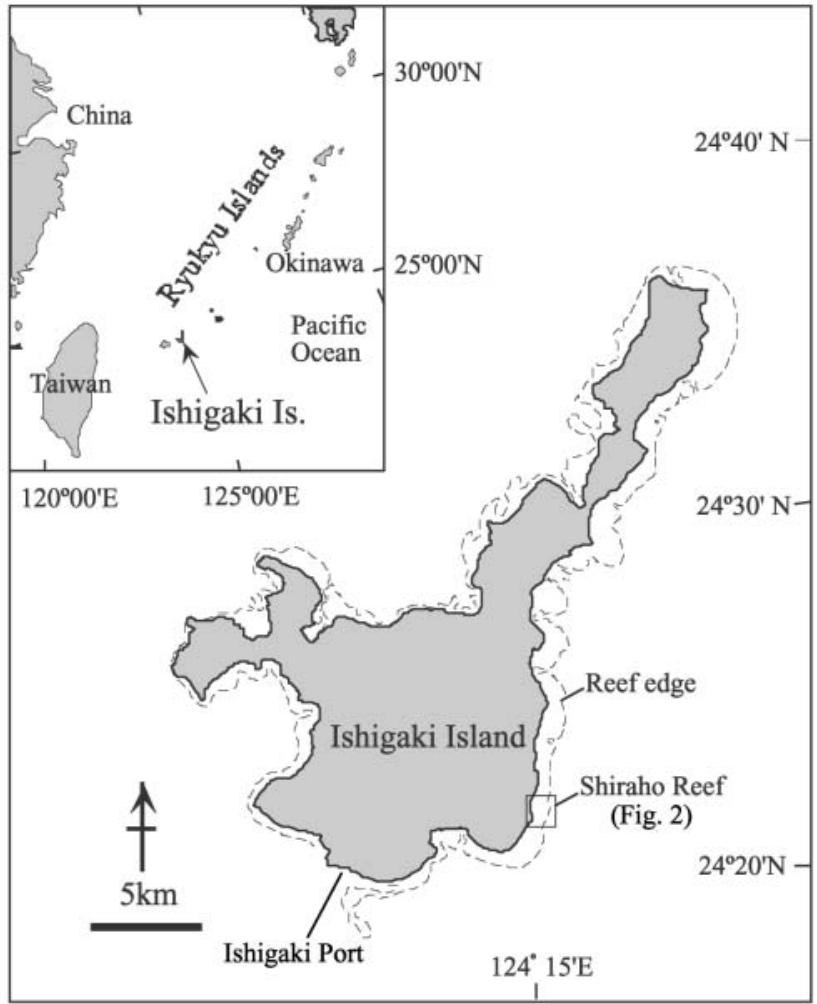

Fig. 1. Study site, Shiraho Reef, located on the southeast coast of Ishigaki Island

close to one of our transects. They reported a dense distribution of $H$. coerulea and branching Montipora landward of the reef crest, and Acropora aspera on the reef crest.

From July to August 1998, warm water prevailed over the northwest Pacific and extensive bleaching occurred throughout the Ryukyu Islands and off the south coast of Japan (Yamazato 1999). Bleaching was first observed in early July; it peaked in August and September and ceased in early October (Hasegawa et al. 1999, Yamazato 1999). The sea-surface temperature (SST) in Ishigaki Port was above $30^{\circ} \mathrm{C}$ once in the middle of July and from the middle of August until early September in 1998 (Fig. 3). The SST never exceeded $30^{\circ} \mathrm{C}$ in 1997,1999 , or 2000 , and from July to early September in 1998 it was 1 to $2^{\circ} \mathrm{C}$ higher than in normal years. The time during which the SST exceeded $30^{\circ} \mathrm{C}$ corresponded with the period of bleaching, which confirmed that the major reason for the bleaching of coral in the Ryukyu Islands was the high SST. On the shallow reef flat, the seawater was 2 to $3^{\circ} \mathrm{C}$ warmer than the SST in the outer ocean during the daytime, and it reached $35^{\circ} \mathrm{C}$ in the middle of August (Kayanne et al. 1999).

Transect survey. We examined the coral coverage along 5 fixed transects across the reef flat just before the bleaching (15 to 22 May 1998), during the bleaching (19 to 25 September 1998), and 6 times after the bleaching ( 2 to 8 December $1998 ; 15$ to 23 March, 25 June to 1 July, 20 to 29 September 1999; 28 February to 6 March, 17 to 23 August 2000). The transects were 710 to $800 \mathrm{~m}$ long, perpendicular to the shoreline, and arranged $300 \mathrm{~m}$ apart, parallel with each other (N12 to S12 in Fig. 2). They were fixed using a transit and a laser range-finder from benchmarks on the shore and using landmarks on the reef flat. The strict placement of the transects enabled reproducible surveys of the same coral patches along the transects.

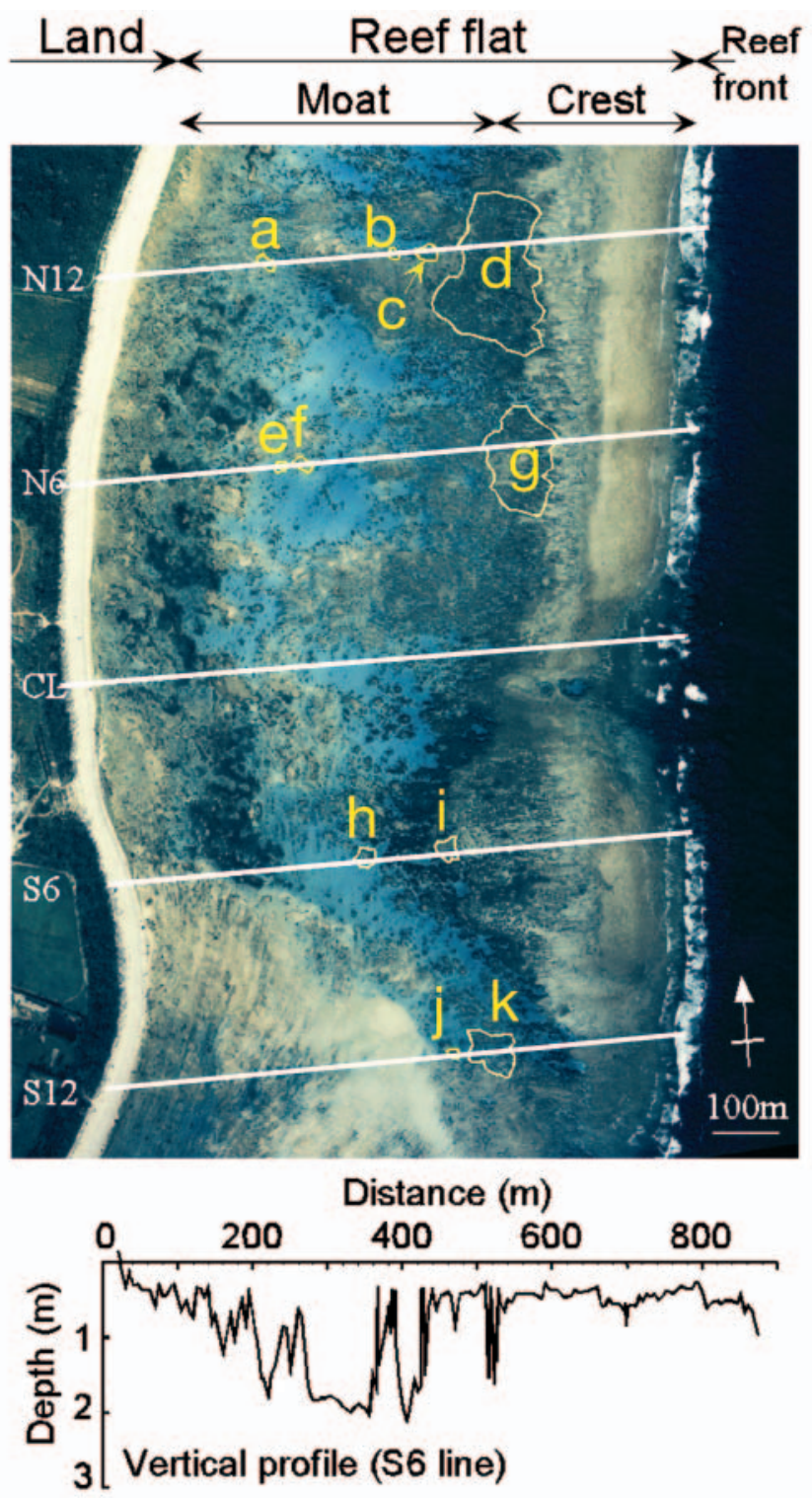

Fig. 2. Aerial photo of Shiraho Reef on the southeast coast of Ishigaki Island, showing the 5 permanent transects (N12 to S12) and a vertical profile along S6. The transects cut across patches of branching Montipora (a to k) 


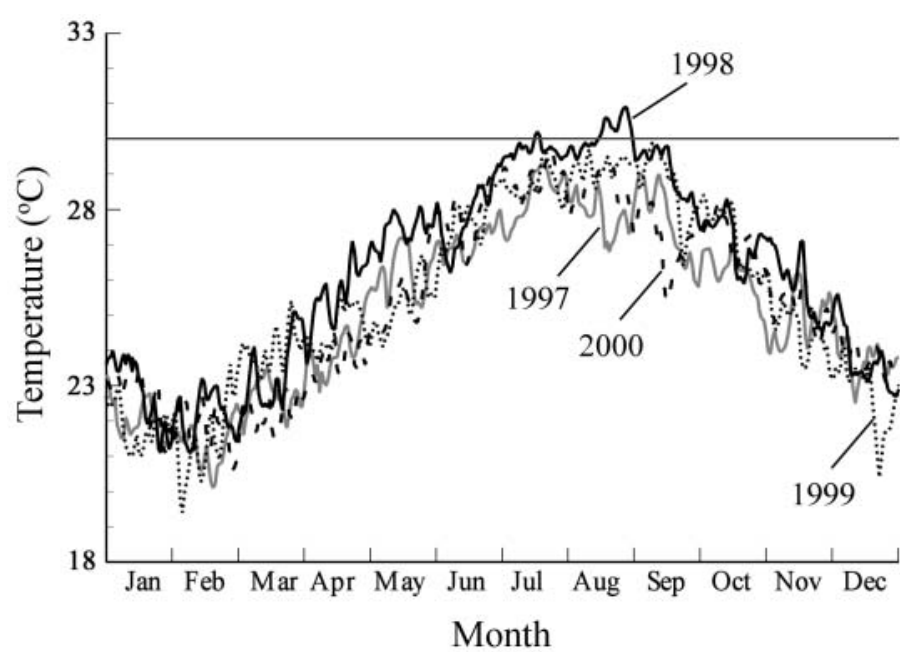

Fig. 3. Changes in sea-surface temperatures in 1997 to 2000 at Ishigaki Port (Japan Meteorological Agency)

The same observer visually determined the coverage of corals every $10 \mathrm{~m}$ in a $1 \mathrm{~m}$-wide strip along each transect. The coverage of each observed species was recorded at $5 \%$ intervals. This is a semi-quantitative method of estimating the coverage of corals, which applies the manta tow survey method (English et al. 1997) more strictly. Each coral species was identified by sampling a minimal amount of the colony. Some coral species were difficult to distinguish in the field, so groups of species belonging to the same genus and ecoform were identified (e.g. massive Porites, branching Montipora, etc.). The visual method was repeatedly compared with quantitative estimates from photographs of the same strip, and with the results of a line-transect method at sites with different coverage. Errors were determined by comparing the visual coverage estimates with the quantitative analysis and these were added to the original interval errors (we recorded the coverage at $5 \%$ intervals; therefore, less than $2.5 \%$ interval information was initially lost). This method enabled repeated surveys of a long transect (a total of $3790 \mathrm{~m}$ ).

Bleached colonies were counted as living in September 1998. The percent coverage of bleached colonies to all the living colonies was estimated along the transects for the dominant species in September 1998. Corals were scored as normal (full color characteristics of the given species in a healthy state), partially bleached (some of the coral colony or population was bleached or there were corals with evident loss of coloration), or bleached (no obvious pigmentation in the coral tissue). The percentage of dead corals was estimated by subtracting the coverage of living corals, including bleached corals, from the coverage in May 1998.
Corals were distributed in patches from several meters to hundreds of meters. The net coral coverage of each patch was estimated by summing the area multiplied by the coverage along the transect as follows:

$$
\sum\left\{10 \mathrm{~m}^{2} \times(\% \text { coverage }) / 100\right\}
$$

The net coverage indicates the relative size of the patches, by multiplying area times density.

\section{RESULTS}

\section{Temporal changes in coral coverage along transects}

Fig. 4 shows the time-series change in the percent coverage of living dominant corals along the 5 transects. The dominant species before the bleaching event were Heliopora coerulea, massive Porites (P. lutea and P. australiensis), branching Porites (dominated by $P$. cylindrica with $P$. nigrescens), branching Montipora (dominated by M. digitata with M. stellata), branching Acropora (dominated by $A$. formosa with $A$. pulchra and A. palifera) and Pavona (dominated by $P$. frondifera with $P$. cactus and P. varians), as shown by the column for May 1998 in Fig. 4. Coverage of other species was less than $5 \%$ throughout the study. All these species are typical species that are found in the Indo-Pacific Ocean.

The corals occurred in patches extending from several to hundreds of meters along the transects, as shown by the peaks in Fig. 4. Heliopora coerulea and branching types of Porites, Montipora and Acropora had a coverage of $40 \%$ behind the seaward reef crest. In the center of some large patches, homogeneous populations occurred, but usually several species of corals coexisted. $H$. coerulea formed a dense population covering $100 \times 400 \mathrm{~m}$ in the southern part of the surveyed area. Massive Porites and Pavona were distributed close to the shore, with coverage of 5 to $10 \%$. The size of Porites colonies ranged from 40 to $60 \mathrm{~cm}$, with a maximum of $200 \mathrm{~cm}$, and those of Pavona from 20 to $40 \mathrm{~cm}$ with a maximum of $80 \mathrm{~cm}$.

During the bleaching period, the coverage of branching Porites, Montipora and Acropora decreased (September 1998 in Fig. 4): the mortality of these corals was $41.1 \%, 55.4$ and 82.4, respectively (Table 1). Approximately two-thirds of the surviving corals of these branching species were completely or partly bleached. Wellpreserved dead branches of the branching species were observed at locations where there had been living branches in May 1998. Some of the dead branches were covered with filamentous brown algae. Although the percent of bleaching was high, the mortality of massive Porites was as low as $11.5 \%$ in September 1998. In contrast, no bleached or dead colonies of Heliopora coerulea were observed along the transects. 
Table 1. Time-series changes in net coverage $\left(\mathrm{m}^{2}\right)$ of corals along the whole transect and their conditions at September and December 1998. SE = standard error for each species or species group. N: normal; PB: partly bleaching; B: bleaching; D: dead. Percent dead coral was calculated from the reduction in coverage since May 1998

\begin{tabular}{|c|c|c|c|c|c|c|c|c|c|c|c|c|c|c|c|}
\hline \multirow[t]{3}{*}{ Species } & \multirow{3}{*}{ May 98} & \multirow{3}{*}{ Sep 98} & \multirow{3}{*}{$\begin{array}{l}\text { Cho } \\
\text { Dec } 98\end{array}$} & \multirow{3}{*}{$\begin{array}{l}\text { ange in } n \\
\text { Mar } 99\end{array}$} & \multirow{3}{*}{$\begin{array}{l}\text { et cover } \\
\text { Jun } 99\end{array}$} & \multirow{3}{*}{$\begin{array}{l}\text { Ige }\left(m^{2}\right) \\
\text { Sep } 99\end{array}$} & \multirow{3}{*}{ Mar 00} & \multirow{3}{*}{ Aug 00} & \multirow{3}{*}{$\mathrm{SE}$} & \multirow{3}{*}{$\overline{\mathrm{N}}$} & \multirow{2}{*}{\multicolumn{3}{|c|}{$\begin{array}{l}\text { Condition } \\
\text { Sep } 98(\%)\end{array}$}} & \multirow{2}{*}{\multicolumn{2}{|c|}{ Dec 98 (\%) }} \\
\hline & & & & & & & & & & & & & & & \\
\hline & & & & & & & & & & & $\mathrm{PB}$ & B & $\mathrm{D}$ & $\mathrm{N}$ & $\mathrm{D}$ \\
\hline Heliopora & 15 & 15 & 14.5 & 14.5 & 14 & 14 & 14 & 13 & 1.3 & 100 & 0 & 0 & 0 & 90.3 & 9.7 \\
\hline $\begin{array}{l}\text { Porites } \\
\text { (massive) }\end{array}$ & 13 & 11.5 & 10 & 10.5 & 11.5 & 11.5 & 11 & 8 & 1.3 & 12.2 & 42.9 & 33.3 & 11.5 & 76.9 & 23.1 \\
\hline $\begin{array}{l}\text { Porites } \\
\text { (branching) }\end{array}$ & 17 & 10 & 8 & 5.5 & 6 & 6 & 6.5 & 6.5 & 1.3 & 26.1 & 16.2 & 16.7 & 41.1 & 47.1 & 52.9 \\
\hline $\begin{array}{l}\text { Montipora } \\
\text { (branching) }\end{array}$ & 46 & 20.5 & 15.5 & 19 & 25.5 & 29.5 & 34.5 & 44.5 & 1.6 & 14.3 & 15.0 & 15.3 & 55.4 & 33.7 & 66.3 \\
\hline $\begin{array}{l}\text { Acropora } \\
\text { (branching) }\end{array}$ & 8.5 & 1.5 & 2 & 2.5 & 3.5 & 3.5 & 2.5 & 4 & 0.9 & 6.4 & 6.4 & 4.9 & 82.4 & 23.5 & 76.5 \\
\hline Pavona & 5.5 & 0.5 & 0 & 0 & 0.5 & 0.5 & 1 & 1 & 1 & 0 & 3.1 & 6.0 & 90.9 & 0 & 100 \\
\hline
\end{tabular}

In December 1998, no bleached colonies were observed, but the coverage had decreased since September. Colonies that were bleached in September were dead or had regained their zooxanthellae by December. Mortality was high for the branching species and Pavona, and low for Heliopora coerulea and massive Porites (Table 1). Massive Porites regained zooxanthella and maintained their coverage. By June 1999, some branching Montipora had started to recover along Transects N12 and N6, and by March 2000 it exceeded its pre-bleaching coverage. On the other hand, some patches of branching Montipora and Acropora had disappeared and these never recovered. Pavona, which was distributed near the shoreline along N12 and N6, had also disappeared.

Fig. 5 shows the change in the net coverage of corals for all the separate patches of 5 different groups. The net coverage (area multiplied by the percent coverage along the transect) corresponds to the size of the patches in Fig. 4. No significant change in coverage occurred between before and after the bleaching for Heliopora coerulea and massive Porites populations (Friedman test; $\mathrm{n}=7, \chi_{\mathrm{r}}^{2}=0.3, \mathrm{p}<0.05$ and $\mathrm{n}=8, \chi_{\mathrm{r}}^{2}=$ 4.7, $\mathrm{p}<0.05$, respectively; Fig. 5A,B). In contrast, significant changes were observed in the coverage of branching Porites and Montipora after the bleaching (Friedman test; $\mathrm{n}=9, \chi_{\mathrm{r}}^{2}=22, \mathrm{p}<0.05$ and $\mathrm{n}=11, \chi_{\mathrm{r}}^{2}=$ 21, p $<0.05$, respectively; Fig. 5C,D).

\section{Recovery of branching Montipora as a function of patch size}

Branching Montipora was susceptible to bleaching, and its mortality after bleaching was as high as $66.3 \%$ (Table 1). However, the coverage of branching
Montipora increased measurably in the 7 mo after bleaching and returned to pre-bleaching levels within $2 \mathrm{yr}$ in some patches (Patches $\mathrm{d}, \mathrm{g}, \mathrm{k}$, and $\mathrm{c}$ in Figs. 4 \& 5D). Branches of recovering Montipora, 5 to $15 \mathrm{~cm}$ long, were observed growing upward on dead Montipora skeletons in August 2000. In contrast, living corals virtually disappeared from some patches (Patches a, b, e, f, h, i, and j in Figs. 4 \& 5D). Patches $e, h, i$, and $j$ vanished, and the only signs of their previous existence were dead branches covered with sand and algae.

Branching Montipora was distributed in patches ranging from several meters to $100 \mathrm{~m}$ wide on the reef flat, with a coverage of 5 to $40 \%$ before the bleaching (Fig. 4). Our transects cut 11 patches (Patches a to $\mathrm{k}$ ) virtually across the centers of the patches (Fig. 2); therefore, the length along the transect reflects the approximate size of the patches. Table 2 shows patch size along the transect and the

Table 2. Montipora spp. Time-series of changes in net coverage $\left(\mathrm{m}^{2}\right)$ of various sized-patches. ${ }^{*}$ Patches that recovered

\begin{tabular}{|lcrrrrr|}
\hline \multirow{2}{*}{$\begin{array}{c}\text { Patch } \\
\end{array}$} & $\begin{array}{c}\text { Transect } \\
\text { no. }\end{array}$ & $\begin{array}{r}\text { Patch size } \\
(\mathrm{m})\end{array}$ & \multicolumn{5}{c}{ Change in net coverage } \\
& & & $\left.\mathrm{m}^{2}\right)$ \\
\hline $\mathrm{a}$ & $\mathrm{N} 12$ & 20 & 2 & 1 & 0.5 & 0.35 \\
$\mathrm{~b}$ & $\mathrm{~N} 12$ & 10 & 1 & 0 & 0.5 & 0.25 \\
$\mathrm{C}^{*}$ & $\mathrm{~N} 12$ & 30 & 2.5 & 1 & 3.5 & 0.43 \\
$\mathrm{~d}^{*}$ & $\mathrm{~N} 12$ & 100 & 20.5 & 7.5 & 21.5 & 0.79 \\
$\mathrm{e}$ & $\mathrm{N} 6$ & 10 & 1 & 0.5 & 0 & 0.25 \\
$\mathrm{f}$ & $\mathrm{N} 6$ & 20 & 2 & 1 & 0.5 & 0.35 \\
$\mathrm{~g}^{*}$ & $\mathrm{~N} 6$ & 70 & 3.5 & 3.5 & 12 & 0.66 \\
$\mathrm{~h}$ & $\mathrm{~S} 6$ & 50 & 1.5 & 0 & 0 & 0.56 \\
$\mathrm{i}$ & $\mathrm{S} 6$ & 40 & 2.5 & 0 & 0 & 0.5 \\
$\mathrm{j}$ & $\mathrm{S} 12$ & 10 & 4 & 0 & 0 & 0.25 \\
$\mathrm{k}^{*}$ & $\mathrm{~S} 12$ & 70 & 5.5 & 1 & 6 & 0.66 \\
\hline
\end{tabular}




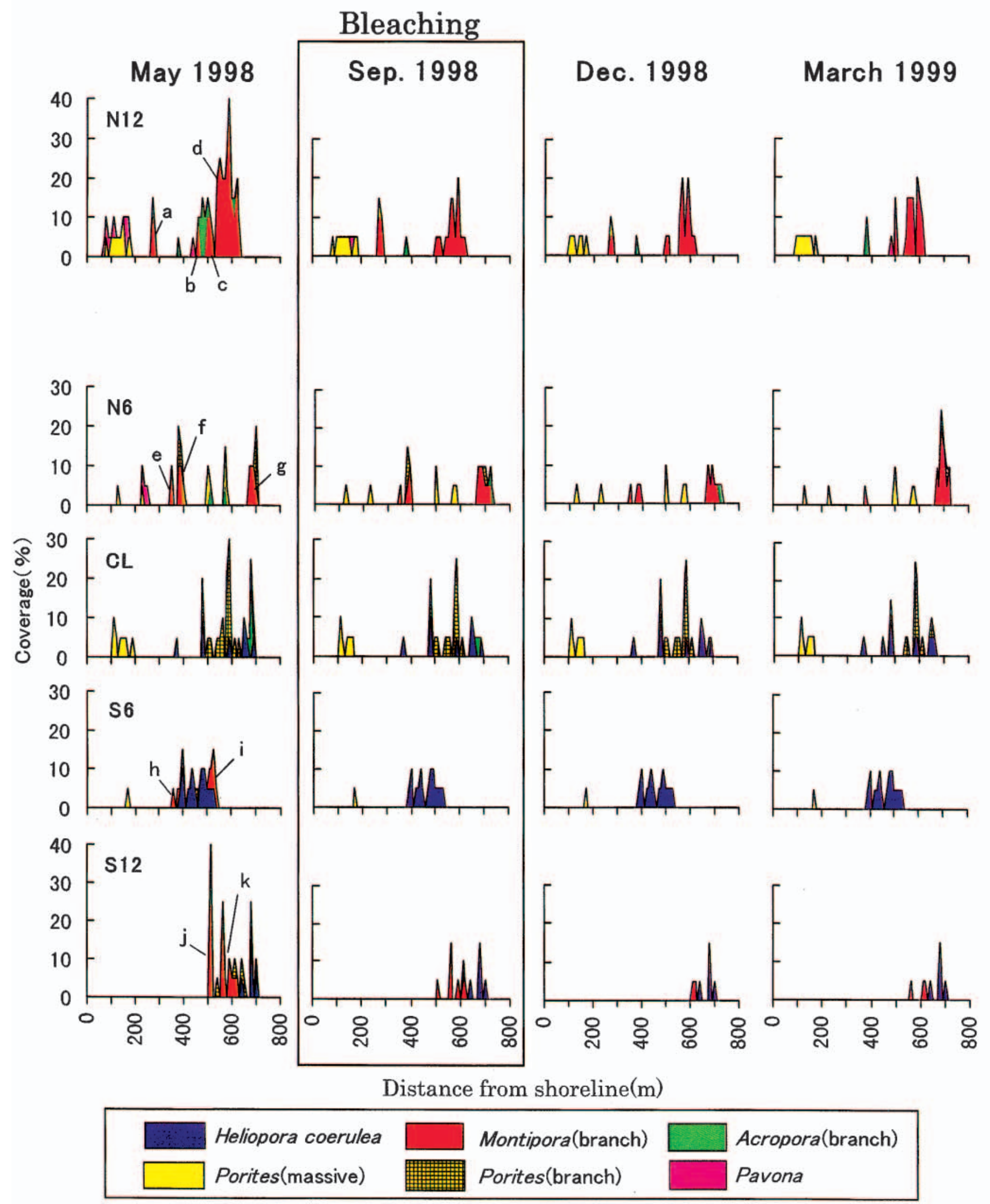

Fig. 4. Time-series changes in coral coverage along 5 transects on Shiraho Reef. In 1998, bleaching lasted from late July to early October; no colonies appeared to be bleached in May or after December. a to k: patches of branching Montipora corresponding to those in Fig. 2. (Data from May 1998 to March 1999 from Kayanne et al. 1999) 

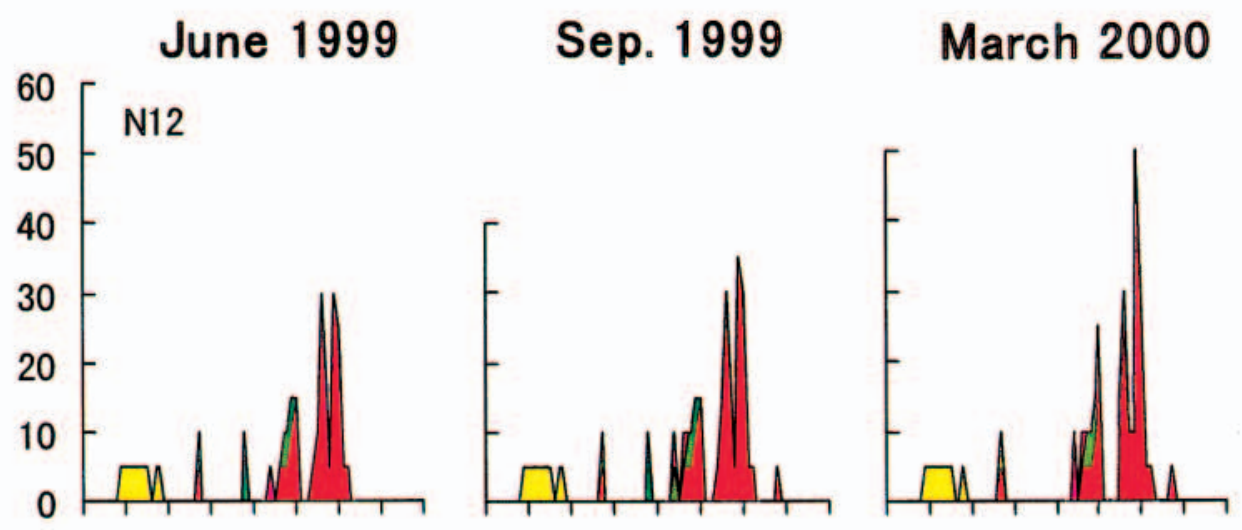

Aug. 2000

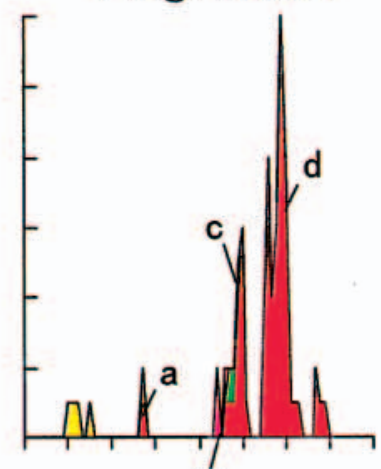

(b)
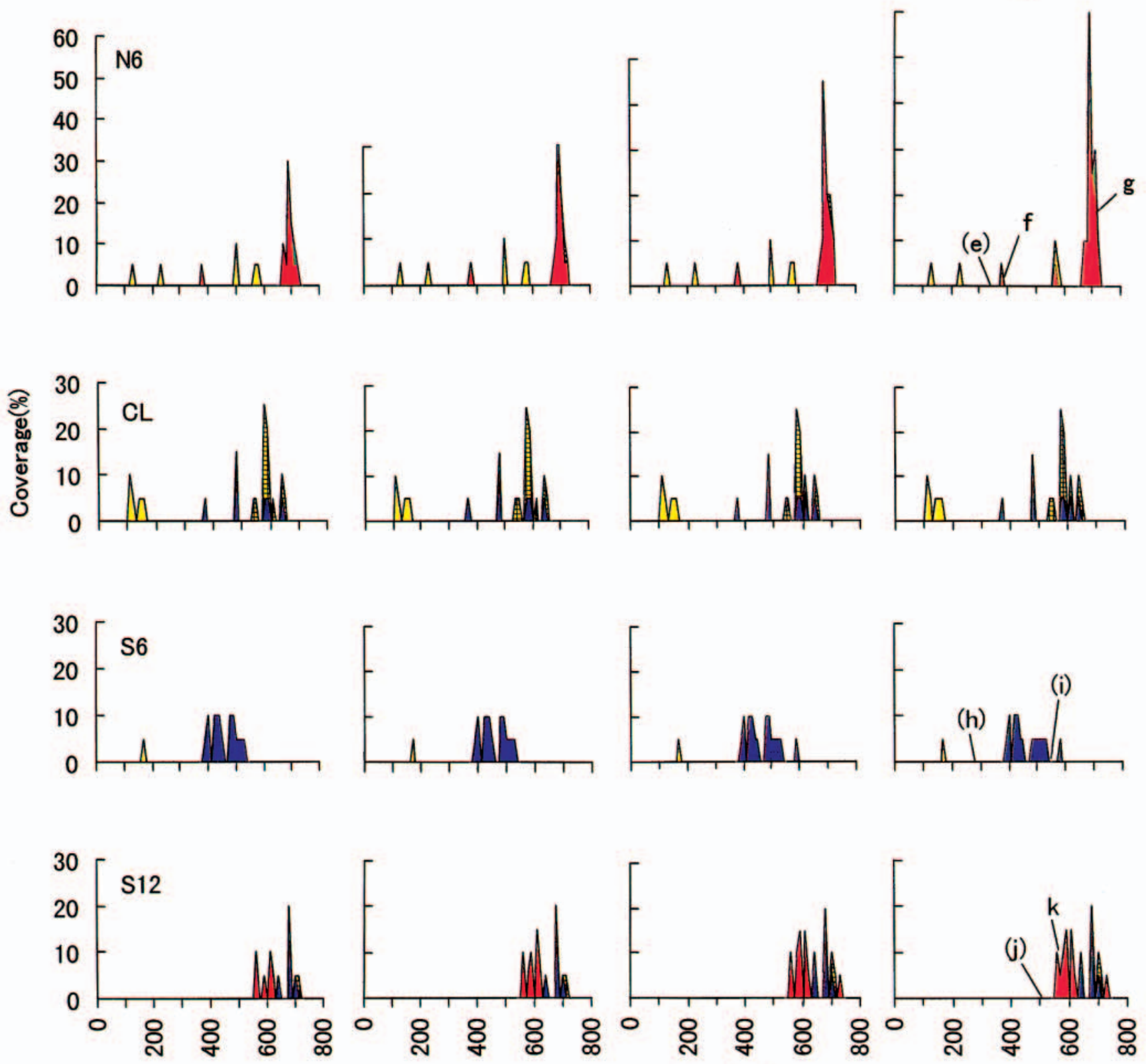

Distance from shoreline(m) 

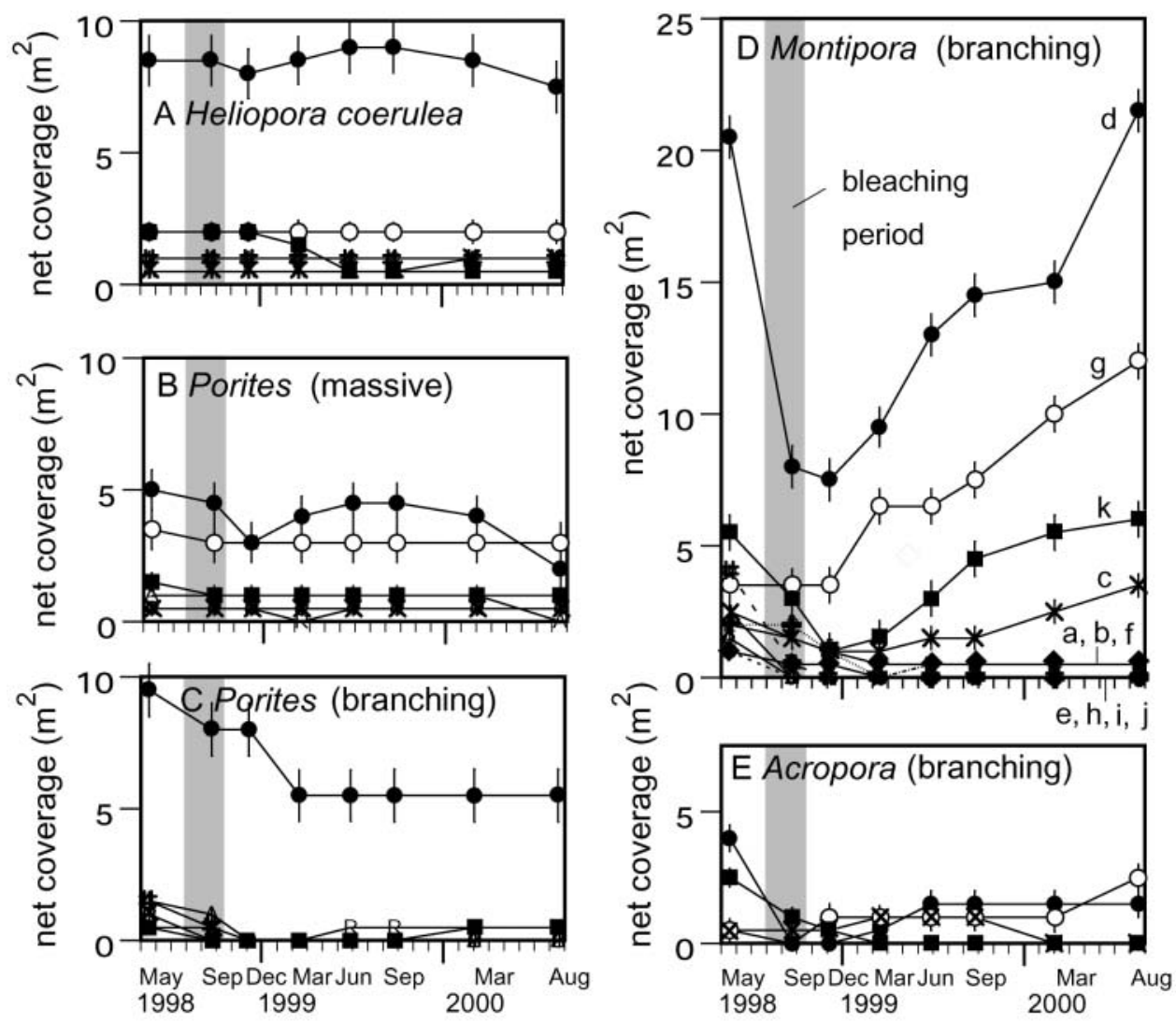

Fig. 5. Changes in net coral coverage of patches of Heliopora coerulea (A), massive Porites (B), branching Porites (C), branching Montipora (D), and branching Acropora (E) from May 1998 to August 2000. Bleaching (shaded bars) was from late July to early October 1998. Bleached colonies were counted as living on September 1998. a to k: patches of branching Montipora corresponding to those in Figs. 2 \& 4

values of net coverage for each patch of Montipora at 3 periods of time: during the bleaching (May 1998), just after the bleaching when mortality was highest (December 1998), and $2 \mathrm{yr}$ after the bleaching (August 2000). Between May and December 1998, no patches increased their net coverage. Between December 1998 and August 2000, the larger patches had increased their net coverage (Spearman's correlation coefficient; $\left.\mathrm{n}=11, \mathrm{r}_{\mathrm{s}}=0.654, \mathrm{p}<0.025\right)$. The mean sizes of the recovered and diminished patches were $67.5 \pm 28.7 \mathrm{~m}$ and $22.9 \pm 16.0 \mathrm{~m}$, respectively. Recovery was observed in patches that measured more than $70 \mathrm{~m}$ along a transect, with an average coverage of 10 to $40 \%$, corresponding to a net coverage of 3.5 to $20.5 \mathrm{~m}^{2}$ (Patches $\mathrm{d}, \mathrm{g}$, and k). Patches that measured less than $30 \mathrm{~m}$ along a transect, corresponding to a net coverage of 1 to $4 \mathrm{~m}^{2}$, did not recover (Patches a, b, e, f, h, i, and j in Fig. 5). Patch c was only $30 \mathrm{~m}$ long, but its coverage was high $(15 \%)$ and it started to recover within $1 \mathrm{yr}$ after bleaching. The larger patches started to recover before the smaller ones.

\section{DISCUSSION}

\section{Species differences in response to bleaching and changes in population structure}

There were clear differences in the susceptibility and recovery among the various species of coral on Shiraho Reef. Heliopora coerulea was the least susceptible to bleaching, while massive Porites was susceptible to, but tolerant of, bleaching, and regained symbiotic algae after the thermal stress ceased. Branching Porites, Montipora, and Acropora were susceptible to bleaching, and their mortality after bleaching was high. Branching Montipora had a high potential for recovery after mortality. Susceptibility to bleaching is reported to be high for branching corals (e.g. Acropora, Montipora, and Pocillopora) and low for massive corals (e.g. Porites and Favia) (Harriott 1985, Brown \& Suharsono 1990, Gleason 1993, Davies et al. 1997, Hoegh-Guldberg 1999, Wilkinson et al. 1999, Goreau et al. 2000, Wilkinson 2000). Differences in susceptibility to bleaching have been explained by differences 
in the morphological structure of the skeleton and tissues of massive and branching corals: the tissues of branching corals form a superficial layer over the corallum, whereas those in massive corals are deepseated in skeletons that can be retracted during periods of stress (Hueerkamp et al. 2001). Our observations on Shiraho Reef confirm previous observations in the literature. Moreover, we should distinguish between susceptibility to bleaching and tolerance after bleaching.

Heliopora coerulea was the species most tolerant of high water temperature on Shiraho Reef. Brown \& Suharsono (1990) observed a reduction in $H$. coerulea after a bleaching event in 1983 in Thousand Islands, Indonesia, although they noted that some colonies might have been removed to construct a small jetty, and thus the reduction might not be attributable to bleaching. The low susceptibility of $H$. coerulea together with the narrow dispersal potential of its planulae (Harii et al. 2002) accounts for its high abundance on Shiraho Reef.

Species with different responses to bleaching coexist on the coral reef flat of Shiraho Reef. The species less susceptible to bleaching, Heliopora coerulea and massive Porites, have the advantage of being able to survive bleaching, but their growth rate is slow (0.7 to 1.1 $\mathrm{cm} \mathrm{yr}^{-1}$ for small colonies of massive Porites in Ishigaki Island recorded by Morimoto et al. 1997; 0.2 to $0.5 \mathrm{~cm}$ $\mathrm{yr}^{-1}$ for $H$. coerulea by Planck et al. 1988). Branching Montipora has the advantage of fast recovery after bleaching due to its fast growth rate $\left(3 \mathrm{~cm} \mathrm{yr}^{-1}\right.$ for M. digitata recorded by Heyward \& Collins 1985), but it is susceptible to bleaching, and the resultant high mortality and recovery are constrained by patch size. Higher temperatures would affect the less susceptible species and their survival would be determined by the severity of bleaching. On the other hand, more frequent bleaching and the extent of mortality would have an impact on susceptible species with a high recovery potential.

The question of whether corals with a high growth rate out-compete low growth-rate corals in a situation of repeated bleaching, or whether tolerant species remain dominant in this situation, has already been discussed (Done 1999, Hoegh-Guldberg 1999, Wilkinson et al. 1999). However, even susceptible species have a high potential to regain zooxanthellae after bleaching or to recover after mortality. Therefore, vulnerability to bleaching is not just determined by susceptibility to bleaching. Moderately frequent and severe bleaching might permit the coexistence of both types of corals on the same reef flat, as in the case of Shiraho Reef. If bleaching occurred more frequently, or with greater severity, this coexistence would not be maintained.
In other regions of the Ryukyu Islands, including Ishigaki Island, recovery such as that on Shiraho Reef is not always observed (Hasegawa et al. 1999, Kayanne et al. 1999). The Shiraho reef flat is semiclosed, with a seaward reef crest, and the water on the reef flat is separated from the outer ocean and is stagnant. This results in higher seawater temperatures during the daytime in summer. The bleaching was reported to be less severe for the corals in deep water outside the reefs in Ishigaki (Hasegawa et al. 1999), which suggests that thermal conditions are more severe on a reef flat. The unique sustainability of the coral populations on Shiraho Reef may be explained by physiological or genetic acclimation arising from changes in the coral-symbiotic algal consortia as a consequence of higher thermal stress (Jones 1997, Baker 2001, Glynn et al. 2001, Hueerkamp et al. 2001, Kinzie et al. 2001).

Takahashi et al. (1985) reported a dense population of Acropora aspera in 1983 on the reef crest close to our Transect S6. We observed no large patches of this species before the bleaching in May 1998, neither along the transect nor between transects. The deterioration of this species might be attributable to the severity or frequency of disturbances, such as bleaching, exceeding the threshold of this species. After this bleaching event, Pavona has also disappeared from the transect. Therefore, recovery did not occur in some populations. This could reflect a long-term trend of deterioration or just a shift in the specific composition of coral populations on Shiraho Reef. Observations on a longer time scale are necessary to evaluate this change.

\section{Factors leading to recovery}

The extent of recovery for branching Montipora was correlated with patch size. Each transect contained both recovered and depleted patches, except for Transect S6, along which the 2 patches $\mathrm{h}$ and i were both depleted. The coral reef flat at Shiraho is dominated by a uniform hydrodynamic regime, with the same seawater temperature and chemical factors (Kayanne et al. 1995). Therefore, in general the differences in recovery did not result from spatial variation in the environment, but were determined by patch size. This view is supported by the fact that small patches (b and j) never recovered, although they were situated close to large patches ( $\mathrm{d}$ and $\mathrm{k}$, respectively) that recovered well. The slower recovery of branching Acropora might also have been a consequence of their small patch size (Fig. 5E).

Branches of recovering Montipora, 5 to $15 \mathrm{~cm}$ long, grew upward on dead Montipora skeletons. The growth rate of $M$. digitata has been measured at $3 \mathrm{~cm}$ 
$\mathrm{yr}^{-1}$ (Heyward \& Collins 1985); thus, the recovered branches had grown from parts of the corals surviving the 1998 bleaching. Recovery was accomplished by asexual regrowth of new branches. Large patch size could be of advantage because of the higher probability of surviving branches and homogeneity of the distribution in the center of a large patch, which might accelerate the fast-recovery of the patch. In some fastrecovering patches, not only density but also patch size increased during recovery (e.g. Patches $d$ and $g$ in Fig. 4). This increase in patch size was due to the fragmentation of branching Montipora. Some branching corals extend their habitat by fragmentation, and the recovery process functions effectively as a consequence of this process. Previous studies have focused on the role of recruitment in the recovery of coral populations (Brown \& Suharsono 1990, McClanahan 2000, Guzmán \& Cortés 2001). Fong \& Glynn (2001) simulated the change in size structure of massive coral populations after bleaching. On the other hand, the present study points out the important role of asexual growth and fragmentation of branching corals in the initial stages of recovery; these are characteristics of fast-growing branching species. The role of recruitment will only be apparent after a period of 5 to $10 \mathrm{yr}$.

At least 2 yr are necessary for susceptible species to recover on Shiraho Reef. This period is necessary for the growth of branches to visually increase the density and area of the populations. Guzmán \& Cortés (2001) monitored the recovery process after the 1982 to 1983 El Niño-induced bleaching event in Costa Rica. There, the coral coverage has still not recovered to prebleaching levels, because of repeated disturbances: dinoflagellate blooms in 1985 and warming events in 1987, 1990 to 1995, and 1997 to 1998. The periods between these disturbances were only 1 or 2 yr each probably too short a time for the coral to recover its coverage.

\section{Implications for conservation during global warming}

At least 2 yr are necessary for susceptible species to recover after a bleaching event, and patch size is a determining factor for the recovery of fast-growing species. A patch at least $70 \mathrm{~m}$ wide with an average coverage exceeding $10 \%$ is necessary for recovery. This factor is important when considering the conservation and restoration of coral reefs; either this patch size must be maintained, or sufficient coral transplanted to the depleted patches. The importance of population size for the survival of endangered species was also pointed out by Glynn et al. (2001); our study shows the threshold size for recovery, a factor necessary for practical purposes.
Shiraho Reef survived the 1998 bleaching and is recovering at an unexpectedly fast rate. On the other hand, many other reefs have not yet recovered (McClanahan 2000, Wilkinson 2000). Shiraho Reef was notable for its high species richness and low anthropogenic stress. Differences in the original composition of coral species and in degree of anthropogenic stress (Kühlmann 1988, Planck et al. 1988, Veron 1992), together with possible historical effects of thermal stress, may result in differences in recovery. It has been predicted that severe mass coral bleaching will soon occur every 1 to 2 yr during global warming (HoeghGuldberg 1999). More severe bleaching would kill even tolerant species, and more frequent bleaching would prevent even fast-growing species from recovering.

Acknowledgements. We are grateful to Y. Tanaka, A. Watanabe, Y. Takagi, and A. Muramoto of the University of Tokyo, H. Yamano, and M. Tamura of the National Institute for Environmental Studies, K. Kawate, T. Kito, I. Iwata, H. Ebata, E. Shimabukuro, and Y. Chibana of the Fuyo Ocean Development \& Engineering Company, and to M. Sasaki for field assistance and discussion. This research was funded by Core Research for Evolutional Science and Technology, Japan Science \& Technology (JST) Corporation, and we thank the JST for allowing the present survey immediately after the bleaching.

\section{LITERATURE CITED}

Aronson RB, Precht WF, Macintyre IG, Murdoch TJT (2000) Coral bleach-out in Belize. Nature 405:36

Baker AC (2001) Reef corals bleach to survive change. Nature 411:765-766

Brown BE, Suharsono (1990) Damage and recovery of coral reefs affected by El Niño related seawater warming in the Thousand Islands, Indonesia. Coral Reefs 8:163-170

Davies JM, Dunne RP, Brown BE (1997) Coral bleaching and elevated sea-water temperature in Milne Bay Province, Papua New Guinea, 1996. Mar Freshw Res 48:513-516

Done TJ (1999) Coral community adaptability to environmental change at the scales of regions, reefs and reef zones. Am Zool 39:66-79

English S, Wilkinson C, Baker V (1997) Survey manual for tropical marine resources, 2nd edn. Australian Institute of Marine Science, Townsville

Fisk DA, Done TJ (1985) Taxonomic and bathymetric patterns of bleaching in corals, Myrmidon Reef (Queensland). Proc 5th Int Coral Reef Congr 6:149-154

Fong P, Glynn PW (2001) Population abundance and sizestructure of an eastern tropical Pacific reef coral after the 1997-98 ENSO: a simulation model predicts field measures. Bull Mar Sci 69:187-202

Gleason MG (1993) Effects of disturbance on coral communities: bleaching in Moorea, French Polynesia. Coral Reefs 12:193-201

Glynn PW, Maté JL, Baker AC, Calderón MO (2001) Coral bleaching and mortality in Panama and Ecuador during the 1997-1998 El Niño-Southern Oscillation event: spatial/ temporal patterns and comparisons with the 1982-1983 event. Bull Mar Sci 69:79-109

Goreau T, McClanahan T, Hayes R, Strong A (2000) Conser- 
vation of coral reefs after the 1998 global bleaching event. Conserv Biol 14:5-15

Guzmán HM, Cortés J (2001) Changes in reef community structure after fifteen years of natural disturbances in the eastern Pacific (Costa Rica). Bull Mar Sci 69:133-149

Harii S, Kayanne H, Takigawa H, Hayashibara T, Yamamoto $M$ (2002) Larval survivorship, competency periods and settlement of two brooding corals, Heliopora coerulea and Pocillopora damicornis. Mar Biol 141:39-46

Harriott VJ (1985) Mortality rates of scleractinian corals before and during a mass bleaching event. Mar Ecol Prog Ser 21:81-88

Hasegawa $H$, Ichikawa $K$, Kobayashi M, Kobayashi $T$, Hoshino M, Mezaki S (1999) The mass-bleaching of coral reefs in the Ishigaki lagoon, 1998. Galaxea 1:31-39 (in Japanese with English abstract)

Heyward AJ, Collins JD (1985) Growth and sexual reproduction in the scleractinian coral Montipora digitata (Dana). Aust J Mar Freshw Res 36:441-446

Hoegh-Guldberg O (1999) Climate change, coral bleaching and the future of the world's coral reefs. Mar Freshw Res 50:839-866

Hoegh-Guldberg O, Salvat B (1995) Periodic mass-bleaching and elevated sea temperatures: bleaching of outer reef slope communities in Moorea, French Polynesia. Mar Ecol Prog Ser 121:181-190

Hueerkamp C, Glynn PW, D'Croz L, Maté JL, Colley SB (2001) Bleaching and recovery of five eastern Pacific corals in an El Niño-related temperature experiment. Bull Mar Sci 69:215-236

Jones RJ (1997) Changes in zooxanthellar densities and chlorophyll concentrations in corals during and after a bleaching event. Mar Ecol Prog Ser 158:51-59

Kayanne H, Suzuki A, Saito H (1995) Diurnal changes in the partial pressure of carbon dioxide in coral reef water. Science 269:214-216

Kayanne H, Harii S, Yamano H, Tamura M, Ide Y, Akimoto F (1999) Changes in living coral coverage before and after the 1998 bleaching event on coral reef flats of Ishigaki Island, Ryukyu Islands. Galaxea 1:73-82 (in Japanese with English abstract)

Kinzie RA III, Takayama M, Santos SR, Coffroth MA (2001) The adaptive bleaching hypothesis: experimental tests of critical assumptions. Biol Bull 200:51-58

Kühlmann DHH (1988) The sensitivity of coral reefs to environmental pollution. Ambio 17:13-21

Marshall PA, Baird AH (2000) Bleaching of corals on the Great Barrier Reef: differential susceptibilities among taxa. Coral Reefs 19:155-163

McClanahan TR (2000) Bleaching damage and recovery

Editorial responsibility: Charles Birkeland (Contributing

Editor), Honolulu, Hawaii, USA potential of Maldivian coral reefs. Mar Pollut Bull 40: 587-597

McClanahan TR, Muthiga NA, Mangi S (2001) Coral and algal changes after the 1998 coral bleaching: interaction with reef management and herbivores on Kenyan reefs. Coral Reefs 19:380-391

Mezaki S (1991) The coral reefs of Ishigaki Island. World Wide Fund for Nature Japan, Tokyo, Japan (in Japanese with English abstract)

Morimoto M, Kayanne H, Yonekura N, Abe O, Matsumoto E (1997) Effect of seasonal difference in growth rate on oxygen isotope records of coral skeletons. In: Yonekura N, Kayanne H (eds) Proceedings of the International Symposium on Quaternary Environmental Change in the Asia and Western Pacific Region, M \& J International, Yokohama, p 115

Normile D (2000a) Some coral bouncing back from El Niño (news of the week). Science 288:941-942

Normile D (2000b) Warmer waters more deadly to coral reefs than pollution. Science 290:682-683

Planck RJ, McAllister DE, McAllister AT (1988) Shiraho Coral Reef and the proposed new Ishigaki Island Airport, Japan. International Union for Conservation of Nature and Natural Resources, Morgas Switzerland

Reaser JK, Pomerance R, Thomas PO (2000) Coral bleaching and global climate change: scientific findings and policy recommendations. Conserv Biol 14:1500-1511

Takahashi T, Koba M, Nakamori T (1985) Coral reefs of the Ryukyu Islands: reef morphology and reef zonation. Proc 5th Int Coral Reef Congr 3:211-216

Vargas-Ángel B, Zapata FA, Hernández H, Jiménez JM (2001) Coral and coral reef responses to the 1997-98 El Niño event on the Pacific coast of Colombia. Bull Mar Sci 69:111-132

Veron JEN (1992) Hermatypic corals of Japan. Aust Inst Mar Sci Monogr Ser 9

Wilkinson C (1998) The 1997-1998 mass bleaching event around the world. In: Wilkinson C (ed) Status of coral reefs of the world: 1998. Australian Institute of Marine Science, Townsville, p 15-38

Wilkinson C (2000) The 1997-98 mass coral bleaching and mortality event: 2 years on. In: Wilkinson C (ed) Status of coral reefs of the world: 2000. Australian Institute of Marine Science, Townsville, p 21-34

Wilkinson C, Lindén O, Cesar H, Hodgson G, Rubens J, Strong AE (1999) Ecological and socioeconomic impacts of 1998 coral mortality in the Indian Ocean: an ENSO impact and a warning of future change? Ambio 28:188-196

Yamazato K (1999) Coral bleaching in Okinawa, 1980 vs. 1998. Galaxea 1:83-87

Submitted: September 27, 2001 ; Accepted: April 30, 2002

Proofs received from author(s): July 31, 2002 